\title{
23/ 25 Years of Alternation, and the African Digital Humanities: Capacity, Communication, and Knowledge-Power ${ }^{1}$
}

\section{Johannes A. Smit Denzil Chetty}

\begin{abstract}
This article condenses the presentation by Prof J.A. Smit, as the International Open Access keynote lecture, of 23 October 2017. It forms the first of a doublebarrel article that seeks to open up some research possibilities with regard to the subject and knowledge-power ${ }^{2}$. Drawing on Foucault, it firstly provides a theoretical framework that may assist in assessing the significance of Alternation, followed by a positioning of the questions Foucault raised through his nearly twenty years of research on this matter, in the digital, or electronic age, specifically with regard to the African Digital Humanities. It then briefly reflects on some of the founding ideas and provides a sample of the historical events in the history of Alternation (1994 - 1996), followed, by positioning it in the international dynamics of the digital age, and the move from Humanities Computing in Alternation, to the Digital Humanities. The fifth focus, and as part of the Conclusion, briefly reflects on Berners-Lee's pioneering vision, as well as the most basic definition of the Digital Humanities, which provides a broad framework of both the past and future research of Alternation.
\end{abstract}

Keywords: Alternation, subject of knowledge-power, aptitude/ capacity/ capabilities, communication, knowledge-power, e-subject, e-communication, e-network, African Digital Humanities (ADH), e-Humanities, e-Human

${ }^{1}$ Open Access Lecture, 23 October 2017.

${ }^{2}$ The second article is titled, 'The African Digital Humanities and Alternation on the UKZN OJS Platform (2018 -): Innovation, Pan-African Collaboration, and Trans-Continental Integration'. 


\section{Introduction}

This article condenses the presentation by Prof. J.A. Smit, as the International Open Access keynote lecture, of 23 October 2017. It is published now, since it has transpired, that it was not a one-off event, and followed by the 2018 Open Access lecture, which is also published this year (cf. Smit \& Chetty 2018).

The current article captures two main focuses of the original title, and presentation. Originally, it included a section on 'How to move peer-reviewed journals edited by scholars at UKZN, to the Online Journal Editing System (OJS) onto the UKZN Platform'. Since, locally, this event of founding the Open Access Platform at the University of KwaZulu-Natal, is very significant on its own terms, and in terms of its own historical trajectory - which was addressed in the 2018 lecture - the moving and management of the journals on the UKZN Open Access Platform will not only be a continuing process, but is a historical event too, in its own right. Since this system will doubtlessly continue to grow into the future, we have therefore decided, that because of the length of the article to present it as two individual articles, each standing on its own, and, together, capture aspects of the original presentation.

In this first article, and drawing on Michel Foucault, we first address the theoretical framework in which we should not only understand the significance of Alternation - at least partly -, but also the African Digital Humanities (cf. Smit \& Chetty 2014). As we continue to address and expand our inter- multi- and trans-disciplinary range, we need to do this in the face of the challenges that the rapidly increasing and expanding populations of the continent pose. In the academic domain, these articulate with the challenges to chart new paradigms, especially in terms of meeting the challenge of developing knowledge formations that may help us address the actual conceptual needs and challenges that our complex realities represent. As such, it raises the question of the developing of knowledge challenge-maps, both urban and rural focused, that may start to chart knowledge ways and means that may assist not only research, but more specifically teaching and learning on the continent. In this regard the road we have travelled may provide some pointers as to the kinds of opportunities that should be engaged.

Second, and closely related to the first point, is the question of our digital age. How is the question of the subject posed within the digital age, and, drawing on Foucault, what are the challenges in this framework? Granted that this is an extremely complex issue, we only provide some indicators as pointers 
to the perspectives we suggest might be engaged. In both these sections, the question of the how, or the way in which the question of the subject has been and continues to be posed within the knowledge-power complex, is addressed.

Thirdly, we briefly reflect on a very small sample of the historical events in the history of Alternation, followed, fourthly, by positioning it in the international dynamics of the digital age, and the move from Humanities Computing in Alternation, to the Digital Humanities. The fifth focus is on a sample of the opportunities that the Digital Humanities have opened up for the Humanities, or more specifically the possibilities and potential that we see in what we may also call the e-Humanities, or the future of the e-Human in Africa.

\section{Theoretical Framework: The Subject of Knowledge-Power}

Reflecting on his academic interests and engagements of the last twenty years, in 1982, Michel Foucault (1982) explains that his general theme of study has not been power, as many were being made to believe ${ }^{3}$. Rather, his researches of the primary discursive formations that gave birth to modern knowledge systems via both his archaeological $^{4}$ and genealogical ${ }^{5}$ method-logical

${ }^{3}$ Where appropriate, references to this text by Foucault, is only referred to by page numbers.

${ }^{4}$ On Foucault's archaeological method, where he has addressed the discursive trajectories of 'Language, Labour, and Life', or, as they are also known in English, as the 3 Ls from his study of the eighteenth century 'systems of thought' in his The Order of Things (OT) (Foucault 1970), cf. Smit, forthcoming. As is well-known, The Archaeology of Knowledge (1971) is Foucault's theoretical text, in which he expounded the methodological procedures he has followed in OT, but also in his other earlier, related books. It could well be regarded as his exposition of his 'method in thought' (cf. Smit [1998]).

${ }^{5}$ Following Nietzsche's suggestive approach in his Genealogy of Morals, Foucault developed his own genealogical 'method in thought' in his Discipline and Punish, and History of Sexuality 1, followed by his History of Sexuality 2 and History of Sexuality 3. The genealogical method, mainly references Foucault's tracings of the lines of intellectual descent, present in a very small sample, though quite representative and enlightening, number of scholarly productions, in terms of what he has also called the historical 'systems of thought' in the Human Sciences. 
pursuits, was the subject (p. 327). On the one hand, this focus is different from the Frankfurt School's focus, of divining the kind of rationalism that could be said to be characteristic of modern culture (p. 328). On the other hand, it is also different from the more boring kind of 'universal philosophy' or 'a metaphysics, or an ontology', that traps scholars in the binary of reason and unreason (p. 335; 337; 328). Rather, it links up with Immanuel Kant's questioning, and asking 'what are we' in a very precise moment of history - a question to ask for an analysis of both ourselves, as well as our present, within the broader context of 'the task of philosophy as a critical analysis of our world' (p. 335f).

To ask the question of who we are, or who we are as subjects, in a particular moment in time, like Kant, Foucault avers, is not devoid of the power question, though (p. 336-339). On the contrary, with regard to the relationship between the subject, communication and knowledge, it is quite pervasive, but also very complex ${ }^{6}$. To get some intellectual grip on it through research, it helps, he says, to research it as to its how, what and why ... not only as individualised, critical, analytical perspectives, but also as to the ways in which the how, what and why of knowledge-power relations are intricately interwoven, or 'united' (p. 336). From the perspective of the how, this is the question of the complex problem of how knowledge-power 'circulates and functions'; as well as, how this complex relates to the subject, and subjectivity. More pointedly, it is a question of 'What happens when individuals exert ... power over [self] and others?' How is knowledge-power exerted over 'things'? (p. 337.) To answer this question of the how, of the 'what happens when ...?', Foucault (1982:786f) proposes that we thematise three main issues, i.e. the 'thematics of power', and that we do that relationally, viz. that of,

- aptitudes, or capacity, 'directly, inherent in the body, or relayed by [and through] external instruments' - subjective, bodily capabilities, and laws, structures, ideologies, and institutions ${ }^{7}$;

\footnotetext{
${ }^{6}$ Amongst many others, cf. Mulgan (1991; 2018); and Castells (2009).

${ }^{7}$ Foucault's integrated perspective on institutional capacity and what that entails, in this diagrammatic understanding of the subject, and e-subject, is addressed in the follow-up article, 'The African Digital Humanities and Alternation on OJS (2018 - ): Innovation, Pan-African Collaboration, and TransContinental Integration'. Here the focus is not on the thematics of subjective
} 
- communication, 'that transmit information by means of a language, a system of signs, or any other symbolic medium'; and

- knowledge-power itself, not with regard to whether one has knowledge, or power or not, but with regard to how knowledge circulates in the social body, how it is exerted, and the kinds of effects it has on, or, how it 'conducts', bodies, institutions, and structures.

From the perspective of the subject, and especially as these three focuses are interwoven, integrated, 'united', and thought together, as a thematics of subjective knowledge-power, and not excluding the institutional, it is important to note that these thematics are in play in 'relations between individuals (or groups)' or between 'partners', as well as between individuals in and between institutions. We may think the relational nature of the thematics, further, expand it, and represent their systems of relations, or relational nature, as follows, i.e. within our paradigm of the challenges of the production of knowledge.

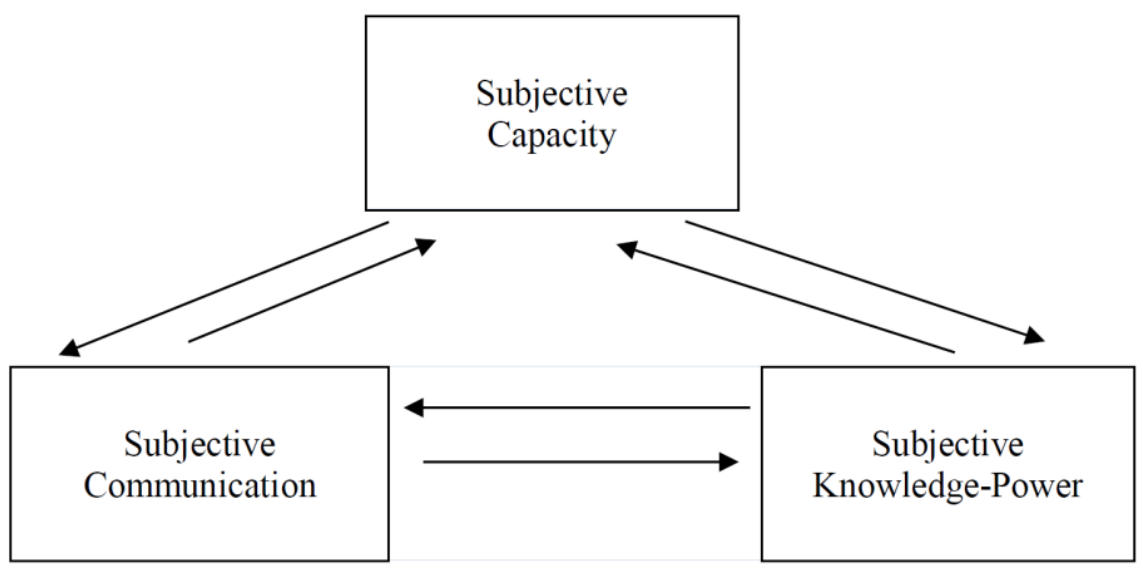

Figure 1: The subject's united, interactive, and integrative relations between capacity, communication, and knowledge-power.

knowledge-power, but a thematics of institutional knowledge-power, and the e-production of knowledge-power, through e-communication networks, including the thinking together of institution and subject and visa versa. 
It needs to be noted that, if we represent these relations as an integrated whole, as above, we do in fact not only raise questions about the focuses in themselves, and their relations, but also questions about the relations, of the relations of these focuses, as well as the complexities these relationalities imply.

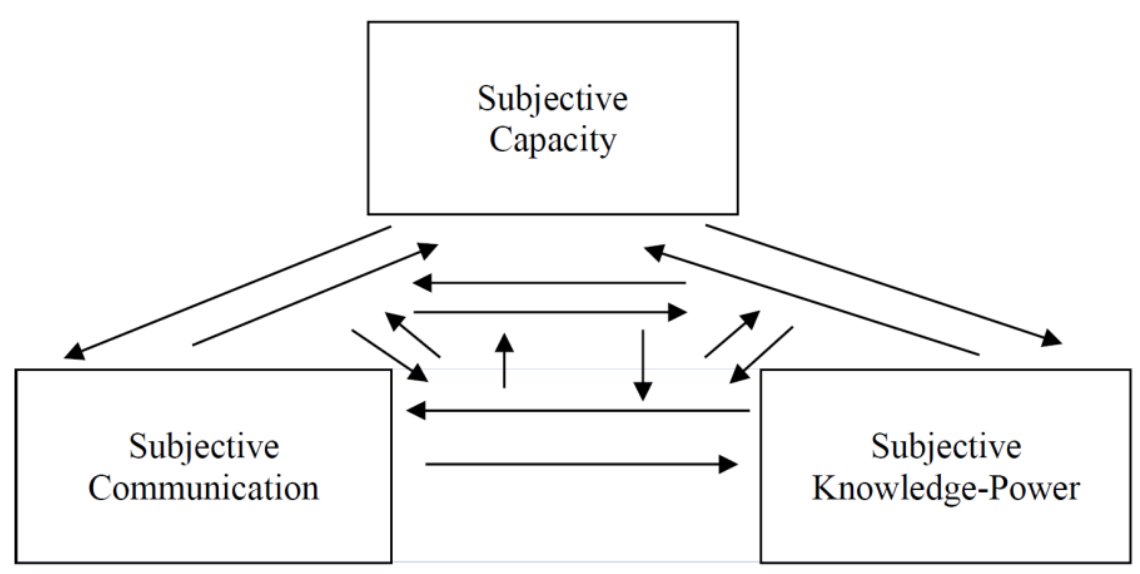

Figure 2: The relations of the relations of the subject's united, interactive, and integrative relations between capacity, communication, and knowledge-power

In Foucault's own explanation, he again thinks from the perspective of the subject, from the perspective of subjective capacity - and, if we include his mention of the body, above, we may call this, subjective, embodied capacity, both personally and institutionally ${ }^{8}$, as these relate via mind, body, and emotions, with both the systems as well as actual embodied communication, and through the relations constituted by knowledge-power. Of these triadic, yet integrated systems of interactive (and inter-subjective) relationships, he says:

It is a question of three types of relationships ${ }^{9}$ that in fact always overlap one another, support one another reciprocally, and use each other mutually as means to an end. The application of objective capacities in their most elementary forms implies relationships of

${ }^{8} \mathrm{Cf}$. also footnote 4 above.

${ }^{9}$ Please note that the italics in this quotation have been added. 
communication, (whether in the form of previously acquired information, or of shared work); it is tied also to [knowledge-]power relations (whether they consist of obligatory tasks, of gestures imposed by tradition or apprenticeship, of sub-divisions or the more or less obligatory distribution of labor). Relationships of communication imply goal-directed activities (even if only the correct putting into operation of directed elements of meaning), and by modifying the fields of information, between partners, produce effects of power. [Knowledge-]Power relations are exercised, to an exceedingly important extent, through the production and exchange of signs; and they are scarcely separable from goal-directed activities that permit the exercise of a power (such as training techniques, processes of domination, the means by which obedience is obtained), or that, to enable them to operate, call on relations of power (the division of labour and the hierarchy of tasks) ${ }^{10}$ (Foucault 1982:787).

Foucault understood the multiply relations and interactions of these processes very well - that of subjective, embodied, capacity, communication and knowledge-power, in terms of how power is exerted over self and otherover 'things'. He continues:

Of course, the coordination between these three types of relationships is neither uniform nor constant. In a given society, there is no general type of equilibrium between goal-directed activities, systems of communication, and power relations; rather, there are diverse forms, diverse places, diverse circumstances or occasions, in which these interrelationships establish themselves according to a specific model (Foucault 1982:787).

${ }^{10}$ From Foucault's examples, we note that there is obviously knowledge involved in these power relations, as he explicate in other writings, i.e. the knowledge that forms part of obligatory relationships, the training of an apprentice, the knowledge that is inherently part and parcel of tradition, knowledge inside the myriad of sub-divisions of labour, the knowledge in and of training techniques, for the whole gamut of professions, the knowledge inherent in processes that exert different forms of domination, and the wide variety of forms of knowledge, that are used for the obtaining, and exertion of obedience. 
Yet, thinking specifically from within and for his own time and context in 1982 - which was, in France, the time of the establishing of forms of socialism vis-à-vis forms of (neo-)liberalism ${ }^{11}$ - he identified the coagulation of the dynamics of these 'diverse forms' of inter-subjective interaction, in 'diverse places, [and] diverse circumstances or [on diverse] occasions', within a specific regime, as constituting knowledge-power blocks. Whereas the subject relations in terms of personal and social capacities, are always moving and developing, and impact actual forms of subjective embodied interaction, and communication via, within and between systems and institutions in diverse spaces, it is possible to have them become regulated, coordinated and routinized in knowledge-power relations blocks - as 'ensembles of actions'. Foucault's example, is that of an educational institution, where,

the disposal of its space, the meticulous regulations that govern its internal life, the different activities that are organised there, the diverse persons who live there, or meet one another, each with its own function,his (her) well-defined character - all these things constitute a block of capacity-communication-[knowledge]power (Foucault 1982:787).

Interactive subjectively-driven knowledge-power systems of relations in which the subject finds itself, in the knowledge-power exerted over self, but also the other, and their relations of relations, and despite being very much in flux, they may find themselves regulated within and by a knowledge-powerblock. Moreover, in addition to the expected learning processes with regard to capacity and communication, as we find in education institutions for example, from knowledge-power perspective, we also have processes of 'enclosure, surveillance, reward and punishment, the pyramidal hierarchy'12 (p. 787).

${ }^{11}$ François Mitterrand, of the centre-left social-democratic political party, Parti socialiste, became President of France in 1981.

${ }^{12} \mathrm{We}$ do not address this matter in this article, and also not, how Foucault's 'thematics of power', or better, 'thematics of knowledge-power' could be used as heuristic device to read his researches from his archaeological, through his genealogical periods, and, how to do that historically. This obviously includes his focus in his genealogical questioning, with regard to the matter of the tracing of lines of intellectual descent (the 'archive') as the 'history of the present', and more specifically, in terms of this article, that of the subjective present. 


\section{The Subject within the Digital Knowledge-Power Framework}

The historicised theoretical framework explicated above, very briefly sums up one of the aspects of Foucault's perspectives in 1982, on his work stretching over a period of more than twenty years. Focusing on relations in which the subject finds itself, and in which it operates and functions, this concerns the explication of the how, of knowledge-power, or, more specifically, the how of the subjective embodied aptitude-communication-knowledge-power complex, or the capacity-communication-knowledge-power complex.

If we fast forward ten years, we find much changed in the world system: the fall of the Berlin Wall in 1989; the dissolution of the Soviet Union on 26 December 1991 - and, with it the nearly seventy years of socialist hegemonies, as well as their totalising threats to the aristocratic Western-liberal capitalist elite -, the fall of the repressive, tyrannical, and degenerate apartheid system, as well as the dawn and rise of the information age, inaugurated by the personal computer, or PC in the late 1980s and early 1990s in South Africa.

Retrospectively, it is certainly the latter, more than any other event or force, that has impacted the world system most decisively, and with that, the knowledge-power complexes of the world. Linked to the then rapid development and installation of intra-institutional and inter-institutional information technology hardware, the PC became the gateway to the global information and knowledge highways of the world. Not only has the PC provided access to international knowledge, it also opened up the digital sharing of knowledge, together with new teaching and learning possibilities. By putting knowledge production at the subject's fingertips, it has simultaneously radically democratised knowledge production. For the first time in modern history, knowledge production was not the prerogative of a soviet-style, or for that matter, an entitled and privileged controlling, and manipulating dominant racist (apartheid) elite. Whereas previously, free thought, free association, free movement, and free speech was only possible under circumstances of severe forms of enclosure, surveillance, reward and punishment - the pyramidal hierarchy, both East and West -, the information highway did away with that. It opened up access to electronic resources, for the advancement of learning in a multiplication of spaces, globally, but also possibilities for the critical, and constructive engagement of local, national and international conundrums that face the world. Information technology freed the thinking (and typing) subject, to constructive knowledge production, for consumption, praxis and usage, while simultaneously refracting hegemonic knowledge-blocks of the world. It 
created the possibilities for a thinking-with on the big, global questions.

Looking back, these dynamics from the late 1980s and throughout the 1990s, opened new freedoms to the populations of the world, and with it, a plethora of opportunities and possibilities, but also a myriad of new challenges, and numerous often intersecting conundrums. We shall not attempt to engage these, or try to provide some kind of challenge-map, for knowledge production in this article at this point. Suffice to say that, from the perspective of the dawn of the information age, and the quantum leaps of the cross-cutting impacts of knowledge production in trans-disciplinary ways since, the question of the subject remains, and that not only with regard to knowledge production as such, but, in terms of Foucault's explications, the intersecting, and interwoven relations in the embodied aptitude-communication-knowledge-power complex, or the embodied capacity-communication-knowledge-power complex. In fact, to pose the question of the embodied subject, today, especially in South Africa with our racist history, may be even more important than in Foucault's own time, on which we shall not much expand in this forum.

Posing Foucault's questions within the electronic, or digital age, raises the question of what we may term the e-Subject, in its multiply networks of relations in e-communication and variable and diverse e-knowledge-power interactions. In terms of the electronic, or digital framework dynamics of the digital age, we may just briefly represent it schematically as in figure 3 below.

More importantly, than posing the questions with regard to the eSubject, as such, is to pose them, not only in terms of the e-Subject's embodied freedoms, and its related aptitudes, or capacities and enhancement and advancements too of capabilities, but especially in terms of its many bodily constrictions, ranging from the continuing legacy of the material inequalities of the modern world, through the multiply forms of surveillance to the holding jobs of remnants of twentieth century systems of race, privilege, and favour. And, as such, to ask these questions today, is to position Foucault's complex of questions in the framework of the electronic age, the digital age, or, speaking in terms of the disciplines, more closer to home, the Digital Arts and Humanities, and more specifically, the African Digital Arts and Humanities, or African Digital Humanities for short. Within this latter context, we believe that academia has not as yet appreciated the rapidly expanding capabilities of the African e-Subject, with regard to the Digital Humanities, and the steadily growing of radically democratic knowledge production sensibilities of the African e-Subject. 


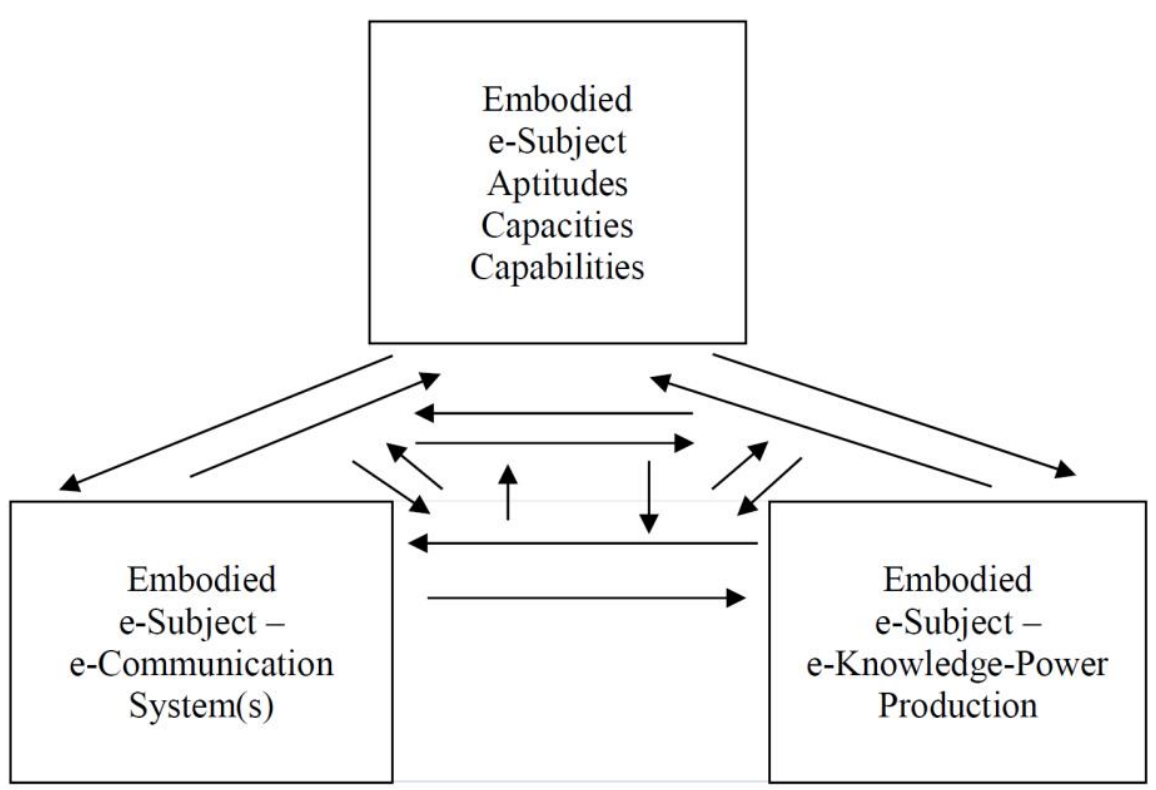

Figure 3: The embodied e-Subject, in its multiply networks of relations in an e-communication and e-knowledge-power framework

In this context, and against the background of the widely recognised increasingly technological future of modern culture, the enhancement and advancement of the e-Subject's aptitudes, capacities, and capabilities should not be understood in mere technical terms. As present in Foucault's careerlong research project, it has become evident that the human subject may yet be re-cognised in the modern world system. And, this should centrally accommodate, and integrate into the rational research, and teaching and learning paradigms, but as re-cognised features of human life and culture, of homo sapiens as such, viz. mind/ the mental; the body/ the physical; and emotion/ feeling in terms of the electronic. Since its inception, this is one of the primary assumptions of Alternation, and has become evident in quite a number of research projects and publications over the years - to move to a more comprehensive and more integrated understanding of the human. As such, and as this trajectory gains traction internationally, also in other spaces, it may yet pose an alternative to the dystopic futures that some historico- 
scientific and evolutionary-biological crystal-ball gazing have charted for world humanity. As meaning making animal, and looking back, homo sapiens has proven itself not only in its story-producing abilities, not least, in his critical self- and national narratives, but also in its abilities and expertise in future scenario constructionisms, where the hard-earned knowledge of the past has been factored in. In this endeavour, the question of the how, how the human and humane e-subject is positioned and interacts within the e-communication and e-knowledge-power networks of both today and the future, not only as participant-consumer, but as knowledge-producer, may yet prove vital for the future of humanity ${ }^{13}$ on Planet A.

\section{23/ 25 Years of Alternation}

In its first ten years, 1994 - 2003, Alternation focused its interdisciplinary approach on the then contextually-relevant problematisations arising from within the scholarly engagements of the Languages and Literatures of Southern Africa $^{14}$. For the next fifteen years, from 2004, to 2018, it opened up its interdisciplinary approaches to include knowledge production from within the programmes and disciplines across the Arts and Humanities, as well as

13 This question of the how, is addressed in both this present article, and the second, related one, 'The African Digital Humanities and Alternation on the UKZN OJS Platform (2018 -): Innovation, Pan-African Collaboration, and Trans-Continental Integration' (cf. footnote 2 above). The question of the what, was addressed in the 2018 presentation, 'Designing Equitable Foundations for Open Knowledge: Freedom, e/Quality \& Access' and will be published in Alternation Special Edition 23 (2018). The ultimately challenge, especially in our current decolonising-of-knowledge-context, concerns the answer to the question: 'How are subjects the producers of knowledge? What do they produce? Why do they produce this knowledge (and no other)? And, how do these together, form integrated processes, with specified outcomes, also impacting institutions of Higher Learning, in the integrated, yet diverse dynamics of knowledge-power productions. This can obviously be asked as historical questions - as Foucault indicated - but also as future-oriented questions, as the decolonising paradigm is challenging us.

${ }^{14}$ For this purpose, it was housed within the Centre for the Study of Southern African Literature and Languages (CSSALL) founded, likewise in 1994. 
Management, Information Technology (IT) and Information Science (IS), and Governance in Southern Africa ${ }^{1516}$.

\subsection{Alternation: Some of the Founding Ideas}

In setting the parameters for Alternation, in the midst of a plethora of theoretical and methodological approaches in the Arts and Humanities (cf. Smit 1995), we identified seven clusters of guiding perspectives, at that historical juncture.

Together with CSSALL, Alternation decided that discursively, all will be equal - i.e. that all will have equal access, and will be equally trained in the requisite discourse needed for the critically-constructive, and contextually-relevant production, and transformation of knowledge, through evidence-based contextually-relevant research-lead Teaching and Learning (cf. Smit \& Chetty 2018:360ff). Most importantly, the legacy of texts banned under the apartheid government, was rectified by studying all equally (even though some remained banned at the time). Examples were, e.g. The Communist Manifesto, and David McLennan's Karl Marx: Selected Readings, and, in literature, for instance, Peter Abrahams's Tell Freedom, and André P. Brink's Afrikaans version of his Kennis van die Aand. We sought to 'normalize' South Africa society. Furthermore, the actual conceptualized production, deployment and use, of the then still banned language - knowledge complexes in method and theory, was shared radically equally. The previously academically dominated, censored and repressed, were released, set free, into equal inter-subjective interaction, and recognition, e.g., students were lead to read, research and critically engage the corpus of excluded and repressed liberation knowledges, not least the indigenous knowledge formations of the peoples of South and Southern Africa.

${ }^{15} 2004$ is the official date of the founding of the new university, the University of KwaZulu-Natal, with its five campuses, including the Pietermaritzburg, Edgewood (Pinetown), Westville, Howard College (Durban) and the Medical School (Durban) campuses. It was the result of the merger of the former Universities of Durban-Westville and Natal. This is also the date at which Alternation's focus was also opened up from a focus on Literature and Languages in Southern Africa, to the Arts and Humanities in Southern Africa. ${ }^{16}$ The title of this article, '23/ 25 Years of Alternation ...', is used to indicate that Alternation was founded in 1994, and that it was approved as international interdisciplinary journal for Southern Africa, by the South African Department of Higher Education in 1996. 
Through these processes, we also opened up a space that recognized the debt that the Humanities of resistance at that time had to both the psychoanalytic and deconstructive paradigms. Ranging from the work of Sigmund Freud, in the early twentieth century, its critical development and deployment in Feminist discursive formations, through the critical works of Michel Foucault, and Jacques Derrrida, to Edward Said, and Homi Bhabha, the view (and practice) was that the de-constructive paradigm (including post-colonial discourse) has become a centrally accepted part of the Human Sciences' approaches to scholarship and the disciplines internationally, and that this should be the case too, in South Africa, as we set out to equalize society and constructively engage its inequalities. It also played a distinctive part in the toppling of apartheid's patriarchal, and racist 'Arts' edifice, which fit the Marxian critique of the Superstructure very well. As such, and amongst others, psychoanalytical and deconstructive approaches would continue to play a role in the continued de-construction of existing apartheid-inherited knowledges and the impacts they have had, and continued to institutionally have in the human sciences. Constructively, and positively, they would provide basic tools of thought for the construction of new knowledge, especially with regard to the fostering of inter-cultural, and inter-racial, equal intra-institutional and interinstitutional scholarly interactions and engagements, not least in research and publication. Needless to say, these processes aimed at simultaneously breaking down the repressive and dominating racial apartheid knowledge barriers and boundaries that separated, excluded and marginalized, often most visibly present in marginalized literatures, languages and knowledges ${ }^{17}$.

We also recognized the world-historical rise in the acknowledgment of cultural difference, in so far as existing forms of cultural difference have been humanly created, as very often forms of domination, exploitation, and exclusion, and the global recognition of culture as always in flux, and being characterized by its hybridity. The main focus of the approach of Alternation, as an interdisciplinary approach - which included what is today called transdisciplinary - must be understood in this framework, and then, to develop interdisciplinary approaches as discursive practices. By focusing on Southern

${ }^{17} \mathrm{Cf}$. for instance the Alternation issue edited by Mahonga, Van Wyk \& Smit in 1998, Marginal Literatures, Marginal Figures and Marginal Genres in South African Literatures; as well as Smit, Van Wyk \& Wade's Rethinking South African Literary History, 1996. 
African Literature and Languages, the challenge was to produce knowledge with regard to the explicit recognition of the hybridity, and diversity in, and between cultures, and to use psychoanalytic and deconstructive approaches to not only critically study the then existing, knowledge-power blocks (as explicated earlier in this article) but to also produce knowledge outside them, with, and in, and for community, or, the then emerging New South Africa.

In the fourth place, the articulation of CSSALL and Alternation, with the continued untransformed knowledge block(s) that we have inherited from the outdated liberal and apartheid paradigms, posed a problem. As is evident from the current decolonising of knowledge drive not only in Southern Africa, this continues to be a major obstacle in the way of freedom and development, and the challenge for the production of the requisite knowledge(s) to feed in and even lead these multiform processes. In order to capture this decisively critical perspective at the time, we clearly stated that it was different, in so far as it could not be seen as integrative, nor as accommodatory of these knowledge blocks, as is evident in Smit (1995).

Fifth, and closely related to this point was to position Alternation in the non-racial space that has been developing since especially the late 1940s. This was done by linking up with the critical analysis and arguments put forward by David Goldberg's Racist Culture (1993), which is proven to remain an important work given South Africa's racist past, not least in academia.

Sixth, and integrating all of these perspectives and their related sentiments, was the question of the nation, and the nation-state. As can be expected, in the 1990s, there was quite a substantial number of publications that have appeared in print media, both internationally and nationally, addressing and questioning the notion of the nation, not least the nation-state (cf. Bhabha 1990 in Smit 1995; and Makgoba 1998, for instance). And, in order to address this mega-challenge, the question of nationhood, as the New South Africa was emerging from its apartheid past, was centrally addressed in CSSALL's main project, the South African Literary History Project (cf. Smit 1999a; Smit 1999b; as well as Smit and Van Wyk 1998/ 1999; Wade 1994; and Alant \& Van Wyk 1994) ${ }^{18}$.

Ultimately, Alternation's significance, is that it opened up a discursive

${ }^{18}$ This project and the numerous Masters and PhD students CSSALL produced over the ten year period of its existence, will be CSSALL's lasting legacy, and is still in need of research. But cf. below. 
space with its related discursive praxes - integrated with CSSALL - different from the then yet untransformed humanities disciplines and subjects inherited from the outdated liberal and apartheid eras ${ }^{19}$. As such, it was intended as a clean break, a different paradigm, and the entering into a new episteme. This project is still continuing, and expanding (cf. Smit \& Chetty 2018).

\subsection{Alternation: A Brief Timeline (2004 - )}

With the founding of the University of KwaZulu-Natal, The University of Durban-Westville, together with the Centre for the Study of Southern African Literature and Languages, and Alternation were integrated into the new institution. The Alternation Editorial Committee decided to continue publishing Alternation as international interdisciplinary journal, as approved by DoHET in 1996. It also decided to expand the journal's focus and objective, viz. to develop and foster Alternation's interdisciplinary post-apartheid paradigm for the Arts and Humanities in Southern Africa. This was done, and, in 2018/ 2019, Alternation is celebrating its $25^{\text {th }}$ year of existence. It is also publishing a number of issues, celebrating, and critically reflecting on our still young democracy, with a view to present and future challegnes. In this section, we just briefly point to some events in Alternation's trajectory, since 2004.

- $\quad$ Starting in the late 1990s, and continuing into the 2000s, Alternation has decided to establish thematically-focused research groups, with dedicated research project leaders, in the interests of knowledge production via peer-reviewed thematic journal issues. A number of the first issues were dedicated to the first main topic, viz. the Southern African Literature project. For an overview of all the issues dating from 1994, cf.:

http://alternation.ukzn.ac.za/archive.aspx

- In 2008, Alternation was contacted by SABINET, with the request to scan and upload all the Alternation back-issues. We understood that government provided funding for the scanning and digitizing of all the DoHET journals, since their inception, up to and including 2008. It formed part of the Carnegie African Journal Archive Project. And was done under the direction of Ms Erika Janse van Rensburg. The Alternation back issues,

${ }^{19}$ As is generally recognized, both the liberal and apartheid ideologies, were characterized by their self-serving exclusionary and repressive practices, of primarily a racist elite, that suppressed the episteme of inclusivity and equality. 
of 1994 - 2009 are available at: https://journals.co.za/content/journal/alt

- In 2011, the Alternation Editorial Committee decided to have our own dedicated Alternation website created, and to have all our back issues uploaded on it. This was done, and in January 2012 we opened our Alternation UKZN Joomla website, with the assistance of Mr. Niall McNulty. Quite significantly, and since this website had a counter attached to it, Alternation received more than 100000 hits and downloads of articles in 2012, and more than 50000 in 2013. This number included back-issues.

- We were then requested by the College of Humanities, at UKZN, to move our website to the current platform. This was done under the direction of Mr. Sibongiseni Msomi. And, Alternation has been published as part of our College site, since January 2014. The homepage is available at:

\section{http://alternation.ukzn.ac.za/Homepage.aspx}

- With the opening of the Alternation home page and archive on the College website, it was decided to terminate the Joomla site, since the College site has taken over all the functions of the Joomla site.

- In early 2017, Ms. Faith Bhengu, Principal Librarian at UKZN and Prof. Carol Bertram of the School of Education, UKZN, approached the Academy of Science of South Africa (ASSAf), to provide training in creation of a dedicated Online Journal Management Systems (OJS) site at UKZN, and also to provide editors and editorial teams of national and international journals, with the requisite training to run their journal on the site. ASSAf's Ms. Susan Veldsman and Ms. Ina Smith did the training, and it was done over a two day period, Wednesday 24 - Thursday 25 May 2017, on Westville campus, with around 30 attendees. Subsequent to this meeting, an initial site was created, and journal editors and editorial teams invited to move their journals to the new UKZN OJS digital platform. For an image of the first Alternation masthead on the UKZN OJS platform, cf. figure 4 below.

\subsection{Alternation: Funding}

The main start-up funders of Alternation and initial Alternation projects were: The Centre of Science Development (CSD - the forerunner of the National Research Foundation, NRF); the NRF; Gencor; Anglo-American, Chairman's Fund; the University of KwaZulu-Natal, and the South African Department of Higher Education (DoHET). In addition, many companies and international funders have funded individual Alternation projects over the years. With this issue of Alternation we wish to heartily thank our past and future funders for 
contributing to the founding of an indigenous African, sustainable project, that has benefitted scholarship, and especially the Digital Humanities, immensely, and will definitely continue to do so in future.

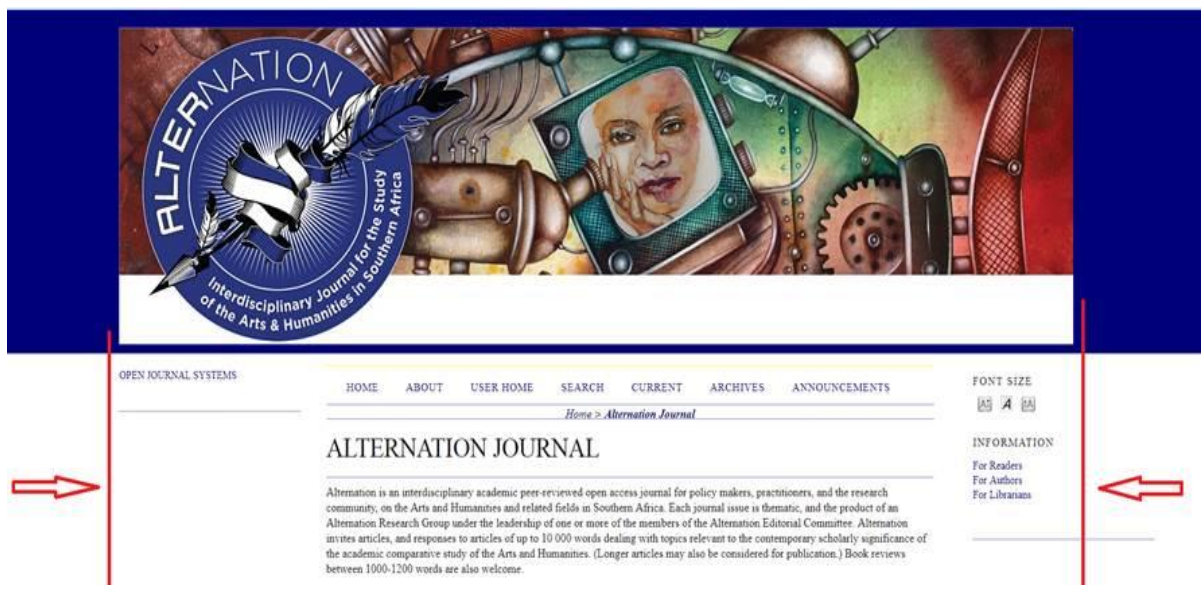

Figure 4: Alternation masthead from 2017.

The updated Alternation site on the UKZN OJS platform, as at December 2018, is available at: http://journals.ukzn.ac.za/index.php/soa.

\section{From Humanities Computing to the Digital Humanities}

As is well-known, and also celebrated in this issue of Alternation, is Tim Berners-Lee's 1989 Proposal for an Information Management System, or, his internet design diagram, or, of a global, interconnected hypertext. At the time, he was a member of CERN, the world's largest particle physics laboratory.

In the early 1990s, the S.A. universities constituted a national, interuniversity committee to research the requirements and viability of both intraand inter-institutional systems for a Southern African Digital Information Technology (IT) network for the planned digital revolution that was in the offing. This was done via the creation of an Educational Information Managing System (EIMS) for South African Higher Educational Institutions (DoE 2001; Mayatula 2007). From the beginning, in 1991, and before the actual founding of Alternation, we were part of this process. And with its founding in 1994, together with CSSALL, the aim was to have its main initial project digitised and published online. Graham Stewart (formerly Dean of Arts, DUT), was the 
IT and IS specialist on the project at the time, and, created the digital online software for the Southern African Literature and Languages Encyclopaedia in the form of a Wiki, with over 35000 entries $^{20}$. Stewart not only did his $\mathrm{PhD}$ on the project, with Johan van Wyk as project leader and supervisor, but also edited an Alternation issue on it, titled, Humanities Computing (cf. 9,2 2002).

In IT and more broadly speaking, IS, Rembrandt Klopper joined the Alternation Editorial Committee in the early 2000s, and took Alternation into the collaborative inter-college research domain, with his inter-university focus research group on Management, IT/ IS and Governance, which had its own dynamics and trajectory. The first two issues were published with the title, Informatics in South African Higher Education I \& II (2005) ${ }^{21}$.

\section{Conclusion}

Following on Berners-Lee's pioneering vision of how to develop what would become the then future digital, or e-Revolution of the late 1990s and early 2000s, the founders of the notion of 'Digital Humanities' (DH) in the early 1990s in the USA collectively constructed the following definition of DH (cf. Digital Humanities n.d.; Kirschenbaum 2010; cf. also Burdick et al. 2012; Drucker 2013; and Terras 2011):

The digital humanities, also known as humanities computing, is a field of study, research, teaching, and invention concerned with the intersection of computing and the disciplines of the humanities. It is methodological by nature and interdisciplinary in scope. It involves investigation, analysis, synthesis and presentation of information in electronic form. It studies how these media affect the disciplines in which they are used, and what these disciplines have to contribute to our knowledge [of computing].

In this brief article, we have attempted to trace some of the processes, or, the how, or the 'what happened' with regard to the still brief history of the

${ }^{20}$ It later became the Encyclopaedia of South African Arts, Culture and Heritage (ESAACH).

${ }^{21}$ In Digital Humanities scholarship, it is widely recognised today that Humanities scholars cannot take place other than including digital expertise. For a very brief overview of the history of the Digital Humanities, see, Vanhoutte's 'The Gates of Hell ...' (2013) for instance. 
beginnings of Alternation. We have also pointed in a quite preliminary and very rudimentary way to some of the developments in Alternation with regard to its positioning within the very broad framework of the Digital Humanities. These have been our small contribution to the Digital Humanities, and, more specifically, with regard to the rationales and positioning of Alternation, within the episteme of the African Digital Humanities, since 1994.

Following the pointers of Immanuel Kant, we have also started this article by very briefly reflecting on Michel Foucault's (1982: 777ff) theorizing of the 'how', the 'what happens', within the broader 'task of philosophy as a critical analysis of our world'. It is especially with regard to the challenges that the decolonising of knowledge on the African continent pose, that the project needs to be inter-, multi-, and trans-disciplinary in nature, be positioned within the electronic framework and technological framework of the digital, and that it should focus on the Humanities, in the form of an African Digital Humanities. In this, the digital-, or e-subject should play a leading role, with regard to capacity development, communication networking, and the production of knowledge. It is only via an 'ensemble of actions', in diverse spaces, in Southern Africa, in Pan-African ways, and also trans-continentally that we shall succeed in producing that yearned-for knowledge(s), we envision through our combined decolonising knowledge projects.

\section{References}

Alant, J. \& J. van Wyk 1994. Word from the Editors. Alternation 1,2 : 1. Available at:

http://alternation.ukzn.ac.za/Files/docs/Alternation\%201.2\%20(1994).pdf

Bhabha, H.K. (ed.) 1990. DissemiNation: Time, Narrative and the Margins of the Modern Nation. In DissemiNation: Nation and Narration. London: Routlege. Available at:

https://www.scribd.com/doc/137781836/DissemiNation-Nation-and-

Narration-Homi-K-Bhabha (Accessed on 21 October 2017.)

Burdick, A., J. Drucker, P. Luhnenfeld, T. Presner \& J. Schnapp 2012. Digital Humanities. London: MIT Press. Available at:

https://mitpress.mit.edu/sites/default/files/9780262018470 Open_Access

Edition.pdf (Accessed on 21 October 2017.)

Castells, M. 2009. Communication Power. Oxford: Oxford University Press.

Department of Education 2001. Education in South Africa: Achievements since 1994. Available at: 
http://www.dhet.gov.za/Reports\%20Doc\%20Library/Education\%20in\%20 South\%20Africa\%20Achievements\%20since\%201994.pdf (Accessed on 23 October 2017.)

Digital Humanities. n.d. Available at:

http://eadh.org/sites/eadh.org/files/DIGITAL HUMANITIES.pdf (Accessed on 21 October 2017.)

Foucault, M. 1982. The Subject and Power. Critical Inquiry 8,4, Summer: 777795. Available at:

https://www.jstor.org/stable/1343197?seq=1\#page_scan_tab_contents (Accessed on 21 October 2017.)

Foucault, M. [1970]1982b. The Order of Things. An Archaeology of the Human Sciences. London: Tavistock. Available at:

https://is.muni.cz/el/1423/jaro2013/SOC911/um/Michel_Foucault_The_O rder_of_Things.pdf (Accessed 21 October 2017.)

Foucault, M. [1971]1972. The Archaeology of Knowledge and the Discourse on Language. New York: Pantheon. Available at:

https://monoskop.org/images/9/90/Foucault_Michel_Archaeology_of_Kn owledge.pdf (Accessed 21 October 2017.)

Foucault, M. [1975]1979. Discipline and Punish. The Birth of the Prison. Sheridan, Alan (trans). London: Penguin. Available at: https://monoskop.org/images/4/43/Foucault_Michel_Discipline_and_Puni sh The Birth of the Prison 1977 1995.pdf (Accessed 21 October 2017.)

Foucault, M. [1978]1984a. The History of Sexuality. Volume I: An Introduction. Hurley, Robert (trans). Harmondsworth: Penguin. Available at: https://suplaney.files.wordpress.com/2010/09/foucault-the-history-ofsexuality-volume-1.pdf (Accessed 21 October 2017.)

Goldberg, D.T 1993. Racist Culture: Philosophy and the Politics of Meaning. Cambridge: Blackwell.

Klopper, R. 2005a \& b. Informatics in South African Higher Education I. Alternation 12,1 a \& b. Available at:

http://alternation.ukzn.ac.za/pages/volume-12/alternation-121a-2005.aspx http://alternation.ukzn.ac.za/pages/volume-12/alternation-121b-2005.aspx

Klopper, R. 2005c. Informatics in South African Higher Education II.

Alternation 12,2 a \& b. Available at:

http://alternation.ukzn.ac.za/pages/volume-12/alternation-122-2005.aspx

Kirschenbaum, Matthew G. 2010. What is Digital Humanities and What is it Doing in English Departments? ADE Bulletin 150:55 - 61. Available at: 
https://mkirschenbaum.files.wordpress.com/2011/03/ade-final.pdf. (Accessed on 21 October 2017.) https://doi.org/10.1632/ade.150.55

Mahonga, L. J. van Wyk \& J.A. Smit 1998. Alternation 5,2. Marginal Literatures, Marginal Figures and Marginal Genres in South African Literatures. Available at:

http://alternation.ukzn.ac.za/pages/volume-5/alternation-5-number-21998.aspx

Makgoba, M. 1998. African Renaissance: The New Struggle. Cape Town: Mafube \& Tafelberg.

Mayatula, S. 2007. Education Management Information System (EMIS): Ensuring Quality through Education Districts. Available at: https://pmg.org.za/committee-meeting/8576/ (Accessed 23 October 2017.) Mulgan, G. 1991. Communication and Control: Networks and the New Economies of Communication. Cambridge: Polity Press.

Mulgan, G. 2018. Big Mind: How Collective Intelligence can Change our World. Princeton \& Oxford: OUP. https://doi.org/10.1515/9781400888511 Smit, J.A. 1995. Introduction. Alternation 2,1: 1 - 4. Available at: http://alternation.ukzn.ac.za/Files/docs/02.1/01\%20Smi.pdf. (Accessed on 23 October 2017.)

Smit, J.A., J. van Wyk, \& J-P Wade (eds.) 1996. Rethinking South African Literary History. Durban: Y-Press. Available at: http://alternation.ukzn.ac.za/Files/resources/jsmit/1996b-RethinkingHistory-and-Literature.pdf

Smit, J.A. \& J. van Wyk 1998/ 1999. Literary Studies in Post-Apartheid South Africa. Culture Link Special Issue: 107 - 125. Available at: http://alternation.ukzn.ac.za/Files/resources/jsmit/1998-1999-LiteraryStudies-in-Post-Apartheid-South-Africa.pdf

Smit, J.A. 1999a. The Dancing Dwarf in the Land of Spirits. (The Beginnings of a Southern African Literary History.) Durban: CSSALL. Available at: http://alternation.ukzn.ac.za/Files/resources/jsmit/1995-1999ai-TheDancing-Dwarf-from-the-Land-of-Spirits.pdf

Smit, J.A. 1999b. Body, Identity, Sub-cultures and Repression in Texts from Africa. Durban: CSSALL. Available at: http://alternation.ukzn.ac.za/Files/resources/jsmit/1997-1999b-BodyIdentity-Sub-cultures-and-Repression-in-Texts-from-A.pdf

Smit, J.A. \& D. Chetty 2014. Reimaging the Humanities in the Twenty-first Century: Towards an Interdisciplinary and Collaborative 'Digital 
Humanities' in Africa. Alternation 21,2: 176 - 206. Available at: http://alternation.ukzn.ac.za/Files/docs/21.2/09\%20Smi.pdf. (Accessed on 21 October 2017.)

Smit, J.A. \& D. Chetty 2017. A Step-by-Step Guide to Creating a 'Back Issue' on UKZN OJS. Circulated to ASSAf's OJS members nationally, and published online by the UKZN library. (Forthcoming.)

Smit, J.A. \& D. Chetty 2018. The African Digital Humanities and Alternation on the UKZN OJS Platform (2018 -): Innovation, Pan-African Collaboration, and Trans-Continental Integration. Alternation Special Edition 21: 360ff. https://doi.org/10.29086/2519-5476/2018/v25n1a15

Smit, J.A. (forthcoming.) Cultural Inclusivity and Decolonisation. Keynote theoretical paper delivered on 15 August 2018, as part of the Panel on Witchcraft, Annual ASRSA Congress, 15 - 16 August 2018, Howard College Campus, Durban, South Africa.

Stewart, G. 2002. Humanities Computing. Alternation 9,2. Available at: http://alternation.ukzn.ac.za/pages/volume-9/alternation-9-number-22002.aspx

Terras, M. 2011. Quantifying Digital Humanities. UCLA Center for Digital Humanities. Available at: http://www.ucl.ac.uk/infostudies/melissaterras/DigitalHumanitiesInfographic.pdf. (Accessed on 21 October 2017.)

Vanhoutte, E. 2013. The Gates of Hell: History and Definition of Digital Humanities Computing. In Terras, M., J. Nyhan \& E Vanhoutte (eds): Definining Digital Humanities: A Reader. Farnham: Ashgate.

Wade, J-P. 1994. Introduction. Alternation 1,1: 1 - 7. Available at:

http://alternation.ukzn.ac.za/Files/docs/Alternation\%201.1\%20(1994).pdf.

Johannes A. Smit

Editor-in-Chief: Alternation University of KwaZulu-Natal

smitj@ukzn.ac.za

Denzil Chetty

College of Human Sciences

Assistant Editor: Alternation University of South Africa (UNISA) chettd@ukzn.ac.za 